\title{
O critério material do IPVA e a ausência de lei complementar ${ }^{1}$
}

Fernanda de Abreu Pirotta ${ }^{2}$

Priscila Seugling ${ }^{3}$

\section{Resumo}

\begin{abstract}
A princípio, a incidência do IPVA aparenta ser de simples assimilação, entretanto, a análise mais apurada aponta para algumas dificuldades e questões ainda pendentes que necessitam de uma resposta. Neste sentido, sob a ótica da metodologia da regra matriz de incidência tributária, 0 presente trabalho busca trazer considerações a respeito das controvérsias acerca da definição do critério material determinante da incidência do IPVA, verificando a necessidade de haver a edição de uma lei complementar que defina esta espécie de tributo, evitando conflitos desnecessários e a guerra fiscal entre os Estados-membros.
\end{abstract}

Palavras-Chave: Regra Matriz de Incidência Tributária; IPVA; Critério Material; Veículo Automotor; Lei Complementar.

\section{Introdução}

Dentro do plexo de proposições normativas do ordenamento jurídico brasileiro que se destinam a regular a conduta das pessoas possui grande relevância a análise atenta a respeito das normas que tratam da incidência fiscal, pois as mesmas regulam a forma pela qual o Estado obterá sua principal fonte de arrecadação, isto é, o principal componente do orçamento público: os impostos.

O estudo do Direito Tributário conduz o intérprete à percepção de que a descrição abstrata de um evento jurídico tributário quando subsumida à realidade do fato jurídico não é tão simples quanto aparenta. Isto porque, ao depositar nos textos do direito positivo as significações de seus atos de vontade, o legislador nem sempre constrói de maneira mais adequada as normas jurídicas a serem observadas. Por este motivo, Paulo de

Barros Carvalho apresenta a metodologia da regra matriz de incidência fiscal, como forma de auxiliar o intérprete a identificar nos textos do direito positivo as normas que irão determinar o dever de dar atribuído aos cidadãos. A regra matriz baseia-se no estudo da

1 Trabalho apresentado como parte integrante da avaliação do 40 bimestre para a Disciplina de Direito Tributário da Universidade Estadual de Londrina.

2 Acadêmica do 50 ano do Curso de Direito da Universidade Estadual de Londrina. .

3 Acadêmica do 5o ano do Curso de Direito da Universidade Estadual de Londrina. . 
semântica e implica em isolar as proposições em si, como formas de estruturas sintáticas para identificar exatamente o fato jurídico sujeito à incidência, bem como os sujeitos e quantitativos que compõem a relação jurídica tributária.

É dentro deste quadro que o presente trabalho pretende analisar a incidência do IPVA, o Imposto sobre a Propriedade de Veículos Automotores, buscando aplicar para esta espécie de imposto as informações adquiridas no decorrer do estudo da regra matriz de incidência fiscal e, a partir dela, mostrar as discussões e controvérsias pertinentes ao tema no âmbito da esfera jurídica.

Neste particular, de fundamental relevância para este estudo é verificar as conseqüências advindas da ausência de uma lei complementar para estabelecer a disciplina geral a ser aplicada na incidência do IPVA, especialmente no que tange à definição do critério material, vez que não há um consenso quanto à abrangência da incidência fiscal sobre as aeronaves e embarcações.

\section{A regra matriz de incidência tributária}

Antes de adentrar a problemática suscitada em relação ao Imposto sobre a propriedade de veículos automotores - IPVA é mister tecer algumas considerações acerca da regra matriz, como forma de esclarecer e pontuar os aspectos que serão abordados.

A regra matriz de incidência tributária é uma fórmula abstrata, uma estrutura lógica composta de um antecedente e um conseqüente. O antecedente descreve a norma, nele posicionam-se diretrizes para identificação de eventos portadores de expressão econômica. Conforme descreve Carvalho (2006, p. 88-89), no descritor da norma haverá um critério material (comportamento de alguma pessoa), condicionado no tempo (critério temporal) e no espaço territorial (critério espacial). A proposição lógica conseqüente tem conteúdo prescritor no qual é possível identificar o critério pessoal (os sujeitos ativo e passivo) e um critério quantitativo (a base de cálculo e a alíquota do imposto). A conjunção desses dados indicativos fornece ao intérprete da norma tributária a possibilidade de exibir o núcleo lógico-estrutural da norma-padrão, preenchido com os requisitos significativos necessários e suficientes para o impacto jurídico da exação.

O antecedente da norma tributária reflete a hipótese tributária; o conseqüente, por sua vez, revela a relação jurídica tributária. Como já dito, neste estudo, a análise da regra 168

Revista de Direito PúBlico, Londrina, v. 2, N. 2, P. 167-176, MAio/Ago. 2007. 
matriz de incidência restringir-se-á à apreciação do critério material, visto que sobre este ponto ainda pairam dificuldades para determinar objetivamente a incidência do IPVA.

\subsection{A regra matriz de incidência tributária aplicada ao IPVA}

À luz da regra matriz de incidência fiscal, a norma jurídica tributária que impõe a exigência de pagar o IPVA compõe-se da prescrição contida no art. 155, inc. III, da Constituição Federal de 1988 e dos textos positivados das Leis Estaduais, promulgadas pelas Assembléias legislativas de cada Estado-membro da Federação.

Afere-se das normas supra-citadas que o fato jurídico que deflagra o direito por parte do Estado-membro ou do Distrito Federal de exigir a prestação pecuniária do IPVA ocorre quando o cidadão possui a propriedade de veículo automotor no Estado-membro da Federação, no primeiro dia do ano, ou na data da aquisição por consumidor final, ou na data do desembaraço aduaneiro, via de regra. A partir da concretização do fato descrito nas normas gerais e abstratas, instaura-se um vínculo obrigacional pelo qual o sujeito ativo adquire o direito de exigir a prestação pecuniária por parte do sujeito passivo, o qual, no caso, tem o dever de cumprir.

A dificuldade está em definir precisamente o que abrange o conceito de veículo automotor, visto que as legislações estaduais tratam o assunto de maneira variada, suscitando demandas judiciais e posições doutrinárias divergentes.

\section{0 critério material do IPVA}

O elemento material do antecedente da norma individual e concreta traz para o intérprete uma ação humana expressa por verbo no pretérito, indicando um comportamento passado, que já se consolidou no tempo. (CARVALHO, 2006, p. 129). Com efeito, o critério material é o núcleo da hipótese tributária composto por um verbo e um complemento que permitem a identificação de quais fatos permitem a incidência fiscal (CARVALHO, 2005, p. 257).

No caso do IPVA, o critério material corresponde ao signo lingüístico: "ser proprietário de veículo automotor". Neste contexto, a discussão cinge-se a definir quem a norma entende "ser proprietário" e o que compreende a expressão "veículo automotor". 


\subsection{Propriedade de veículo automotor}

A questão do conceito de propriedade no âmbito da incidência tributária não suscita grandes controvérsias. Segundo Sacha Calmon Navarro Coêlho, no sistema do CTN a posse radica uma hipótese de "fato gerador por extensão", segundo ele, a posse é um estado de fato jurídico que a lei protege em atenção à propriedade. Por esta razão, afirma-se não haver antinomia entre a Constituição e o Código Tributário Nacional no que concerne à enunciação dos eventos tributários que englobam a posse (CARVALHO, 2005, p. 423).

Esta é uma questão já pacificada. Na maioria das leis estaduais quando se cita a propriedade já se faz menção à posse, referindo-se, portanto, à posse ou propriedade, aludindo ao art. 1196 do Código Civil que enuncia: “Considera-se possuidor todo aquele que tem de fato o exercício, pleno ou não, de algum dos poderes inerentes à propriedade".

Da situação referente à posse, decorre uma série de deveres instrumentais, tal como no exemplo de transferência de propriedade, a qual deve ser comunicada ao Departamento de Trânsito - DETRAN para que seja dada baixa no Registro, e que a cobrança seja feita no nome do novo proprietário.

Quanto à incidência, está sedimentado o entendimento de que tanto o arrendatário mercantil quanto o devedor fiduciário configuram no polo passivo da relação jurídica tributária, razão por que os mesmos são obrigados ao pagamento do IPVA no exercício financeiro competente.

\subsection{Definição de veículo automotor}

$\mathrm{Na}$ definição de veículo automotor reside uma das maiores controvérsias relacionadas ao IPVA.

Em virtude da inexistência de uma Lei Complementar hierarquicamente superior, incumbe às legislações estaduais definir o conceito de veículo automotor sujeito à incidência fiscal do IPVA. A discussão quanto a este conceito refere-se ao fato de que as legislações estaduais, em sua maior parte, estendem o conceito de veículo automotor às embarcações náuticas e aeronaves sujeitando-as ao pagamento do IPVA.

Alguns autores entendem não ser possível que a incidência do IPVA inclua embarcações e aeronaves, pois esse imposto estaria adstrito a veículos automotores 
terrestres. Um dos fundamentos teóricos que sustentam este posicionamento é o entendimento de que o IPVA é sucessor da taxa rodoviária única, e, por isso, não se aplicaria à propriedade de barcos e aeronaves. A "taxa” rodoviária única, teve sua exação prevista no ordenamento jurídico brasileiro com a Emenda Constitucional n ${ }^{\circ} 27$, de 28 de novembro de 1985 e gravava a propriedade dos veículos terrestres em razão de seu valor e de sua procedência, inserindo-o na competência dos Estados e do Distrito Federal (ALBUQUERQUE, 2003). Posteriormente, a Constituição da República de 1988 manteve a competência das unidades federativas para exigirem o tributo acerca da propriedade de veículos automotores, consoante se lê no art. 155, inciso I, alínea "c" (MAMEDE, 2002, p. 13).

Além disso, aqueles que defendem a inaplicabilidade do IPVA às embarcações e aeronaves alegam que navios e aeronaves não se vinculam por nenhum ato registral à célula da partição constitucional da receita deste tributo, que é o município, vez que o banco de dados é de registro nacional. Não existe vínculo do registro nem mesmo perante os Estados, visto que existem capitanias de portos que abrangem mais de uma unidade federada. Já o registro aeronáutico é nacional, sem vinculação a Municípios, os quais participam da partilha da receita advinda da arrecadação do IPVA (MAZZONI, 2005).

Outra argumentação é que a legislação do IPVA teve seu campo ampliado para atingir aeronaves por lei ordinária estadual e não por lei complementar como exige a ordem constitucional, no art. 146, inc. III.

Em entendimento diametralmente oposto, Gladston Mamede esclarece que a definição de veículo, e o significado de automotor abrangem todos os veículos que têm movimento intrínseco à estrutura, e que se automovimentam utilizando-se, para tanto, de um motor. Segundo este autor, a Constituição não restringiu a idéia de veículo à movimentação terrestre, o que implica necessariamente a inclusão dos veículos para movimentação pela água e pelo ar. A simples presença de motor no veículo aéreo é o suficiente para a tributação (MAMEDE, 2002, p. 23).

A solução que muitas legislações estaduais trazem para evitar este conflito é incluir em seus textos normativos dispositivos de isenção a fim de tolher a incidência fiscal para essas espécies de veículos automotores. Outras unidades federativas, entretanto, continuam a prever e cobrar o IPVA das aeronaves e embarcações, e os contribuintes insatisfeitos buscam o Judiciário com o objetivo de reprimir a cobrança do IPVA. O entendimento 
predominante é o de que veículo automotor não se limita aos veículos que trafegam nas vias terrestres, mas engloba tudo aquilo que se automove, impulsionado por um motor. Entretanto, há várias decisões em contrário.

Esta divergência denota a necessidade de uniformização dos sistemas normativos relativos ao IPVA, para evitar que os tratamentos diferenciados do imposto por parte das unidades federativas conduzam, na verdade, a um tratamento desigual e injusto que gera a chamada "guerra fiscal", repudiada pelo ordenamento jurídico tributário.

A disparidade entre as legislações estaduais associada à mobilidade do capital financeiro gera uma nociva disputa entre os Estados-membros, fator que infirma a unidade da Federação, contrariamente ao objetivo constitucional.

A possível solução para dissipar o problema da indefinição do critério material da hipótese tributária do IPVA está na edição de uma lei complementar com normas gerais a respeito de seus principais elementos e pontos controvertidos, legislação esta que traria parâmetros para a arrecadação e à distribuição da receita advinda das aeronaves e embarcações.

\section{A inexistência de lei complementar federal instituidora do IPVA}

Ao contrário do que ocorre com os demais impostos, com relação ao IPVA, não há uma lei federal complementar geral regulamentadora, visto que este imposto foi inserido, na competência dos Estados e do Distrito Federal, ao ordenamento jurídico brasileiro com a edição da Emenda Constitucional no 27, de 28 de novembro de 1985, quando ainda não se exigia a edição de uma lei complementar que trouxesse as correspondentes normas gerais. Daí porque estes entes definiram as normas gerais e específicas do IPVA e logo as puseram em prática.

Atualmente, a edição pelos Estados de legislação própria sobre o IPVA tem respaldo legal no artigo 24, § 3 o da Constituição Federal que diz que "inexistindo lei federal sobre normas gerais, os Estados exercerão a competência legislativa plena, para atender as suas peculiaridades". E ainda está amparada pelo art. 34, § 3ㅇ dos ADCT, do qual se subtrai que "promulgada a Constituição, a União, os Estados, o Distrito Federal e os Municípios poderão editar as leis necessárias à aplicação do sistema tributário nacional nela previsto."

Conforme Alexandre de Morais (1999, p. 280): 
A inércia da União em regulamentar as matérias constantes no art. 24 da Constituição Federal não impedirá ao Estado membro ou ao Distrito Federal a regulamentação da disciplina constitucional (competência supletiva). Note-se que, em virtude da ausência de Lei Federal, o Estado membro ou o Distrito Federal adquirirão competência PLENA tanto para a edição de normas de caráter geral quanto específico. Em relação à inércia legislativa da União, em sede de competência concorrente, decidiu o STF que "enquanto não sobrevier a legislação de caráter nacional, é de admitir a existência de um espaço aberto à livre atuação normativa do Estado membro, do que decorre a legitimidade do exercício, por essa unidade federada, da faculdade jurídica que lhe outorga o art. 24 , § $3 \circ$, da Carta Política.

Em que pese ser plenamente constitucional o fato de cada Estado criar a sua própria legislação sobre IPVA, é impreterível que se analise as conseqüências da falta de uma lei complementar sobre o assunto e a sua importância para a instituição de cada tributo no ordenamento jurídico brasileiro.

Sabe-se que a lei complementar possui uma função muito importante no sistema tributário. Através dela são instituídas as normas gerais que irão definir a base de cálculo, os fatos gerados, contribuintes, lançamento, prescrição, decadência, entre outros fatores. Assim está expresso no Art.146, inciso III e alíneas da Constituição Federal de 1988:

Art. 146. Cabe à lei complementar: [...] III - estabelecer normas gerais em matéria de legislação tributária, especialmente sobre: a) definição de tributos e de suas espécies, bem como, em relação aos impostos discriminados nesta Constituição, a dos respectivos fatos geradores, bases de cálculo e contribuintes; b) obrigação, lançamento, crédito, prescrição e decadência tributários; c) adequado tratamento tributário ao ato cooperativo praticado pelas sociedades cooperativas;

Nota-se que a lei complementar, ao editar normas gerais, funciona como instrumento de atuação e desdobramento de nosso sistema constitucional tributário e fator de sua harmonização em todo o território nacional. Logo, os Estados ou os Municípios ao legislar sobre os tributos de sua competência, deverão, em termos conceituais, obedecer a uma mesma disciplina normativa no que diz respeito ao fato gerador, a obrigação tributária, as técnicas de lançamento, a prescrição, a decadência, a anistia, as isenções, etc.

Com relação ao IPVA, a existência da norma geral reguladora resolveria uma série de problemas, como exemplo, aqueles relacionados às alíquotas, que variam e apresentam, às vezes, feitio extrafiscal, sobretudo quando privilegiam utilitários ou veículos nacionais. Sabe-se que muitos contribuintes são atraídos a emplacar seus carros em outros Estados, devido a alíquota reduzida. Repudia-se, no particular, a malsinada guerra fiscal. 
Evitar-se-ia vários pontos de conflitos, diferenças e omissões dos vários sistemas normativos estaduais do IPVA e principalmente o agravamento da insidiosa guerra fiscal entre Estados.

Conforme as palavras de Roque Antonio Carrazza (2000, p.593):

\begin{abstract}
No rigor da verdade científica, pensamos que a lei complementar veiculadora de normas gerais em matéria de legislação tributária, sem suprir a Constituição, nem limitá-la ou retificá-la, pode validamente (porque o sistema jurídico a tanto a autoriza) revestir seu arcabouço com detalhes que escapam à pena - não ao espírito - do constituinte. Cingindo-se a estas providências, segundo entendemos, para que a lei maior, em matéria de conflitos de competência tributária e de limitações a seu regular exercício, seja melhor compreendida e aplicada.
\end{abstract}

Desta forma, não resta dúvida que é imperiosa a criação de uma lei complementar reguladora do IPVA orientada a evitar conflitos entre os entes federativos e entre estes e os contribuintes, principalmente como forma de consignar expressamente o conteúdo lógico descritivo do critério material da hipótese.

\title{
5 Conclusão
}

A hipótese tributária do IPVA é a descrição normativa do evento que, concretizado no plano das realidades materiais, fará irromper a relação jurídica tributária. A hipótese tributária pode ser identificada por três principais componentes lógicos: o critério material, o critério espacial e o critério temporal. Cada um desses componentes, aplicado ao IPVA, demonstra a legitimidade ou não da incidência do imposto sobre determinados fatos da vida.

Uma das principais dificuldades relacionadas ao IPVA consiste em definir o critério material, isto é, o verbo e o complemento que deflagram o enunciado normativo da incidência fiscal. A complexidade no caso se trata em definir o conceito de veículo automotor a fim de saber se sua compreensão abrange além dos veículos terrestres, as embarcações náuticas e as aeronaves.

Em que pese as opiniões divergentes, não se pode concordar com a interpretação de que veículo automotor restringe-se aos veículos terrestres por ser sucessor da Taxa Rodoviária Única. 
É mister salientar que a Constituição Federal instituiu uma nova organização estatal, inclusive no tocante aos tributos, e não restringiu a incidência do IPVA a veículos terrestres. A interpretação restritiva neste caso foge à aferição da real mens legis, consistindo mera especulação. O significado de automotor abrange todos os veículos que têm o movimento intrínseco à estrutura, e que se automovimentam utilizando-se de um motor.

Não há plausibilidade em excluir as aeronaves e embarcações náuticas da incidência do IPVA. Até porque, ao considerar o valor venal desse tipo de veículo, percebe-se que a incidência do imposto sobre os mesmos atende diretamente o princípio da capacidade contributiva, motivo pelo qual isentá-los provoca uma disparidade tributária injustificável.

Ademais, não há que se falar que o critério material não poderia incluir as aeronaves e embarcações porquanto legislação do IPVA teve seu campo ampliado para atingir aeronaves por lei ordinária estadual e não por lei complementar. Neste ponto, é salutar compreender que o artigo 146, III, da Constituição não pode ser interpretado isoladamente, sob pena de punir inferir absoluta ineficácia às normas constitucionais. $A$ verdade é que o IPVA está expressamente previsto na Constituição, e o artigo 155, inciso III confere a competência tributária privativa aos Estados e Distrito Federal para instituí-lo.

O artigo 24, inciso I e seus parágrafos conferem legitimidade ao exercício da competência legislativa suplementar para editar normas gerais sobre direito tributário quando o legislador federal estiver inerte. Da mesma forma, o artigo 34 , parágrafo 3 , do $A D C T$ permite a edição de instrumentos normativos pelos Estados e Distrito Federal necessários à perfeita aplicação de suas competências tributárias.

Certamente, a ausência de uma lei complementar federal com normas a respeito do IPVA se faz sentir nas inúmeras controvérsias suscitadas a respeito de sua incidência. Todavia, no atual ordenamento jurídico, não tem guarida as interpretações normativas que amputam a eficácia das normas constitucionais e tentam suprimir as normas de incidência tributária injustificadamente.

A verdade é que é indubitável a importância da tributação para o exercício das competências estatais. Contudo, é necessário que haja a edição de normas claras a respeito dos tributos, que sejam adequadas aos princípios constitucionais, para que sejam também efetivamente observadas. 


\section{Referências}

ALBUQUERQUE. Marina Câmara. Considerações acerca da exigência prévia de lei complementar para a instituição do Imposto sobre a Propriedade de Veículos Automotores. 2003. Disponível em: <http://jus2.uol.com.br/doutrina/texto.asp?id=2823>. Acesso em: 12 set. 2006.

CARRAZZA, Roque Antonio. Curso de direito constitucional tributário. 14. ed. São Paulo: Malheiros, 2000.

CARVALHO, Paulo de Barros. Curso de direito tributário. 17. ed. São Paulo: Saraiva, 2005. . Paulo de Barros. Direito tributário. 4. ed. São Paulo: Saraiva, 2006.

MAMEDE, Gladston. IPVA - Imposto sobre a Propriedade de Veículo Automotor. São Paulo: Revista dos Tribunais, 2002.

MAZZONI, Cesar Augustus. A ilegalidade da incidência de IPVA sobre aeronaves e embarcações. Disponível em: <http://www.escritorioonline.com.br>. Acesso em: 05 abr. 2005.

MORAIS, Alexandre de. Direito constitucional. 6. ed. São Paulo: Atlas, 1999. 